\title{
Dynamic performance evaluation model based on Set Pair Analysis and
}

\section{its application}

\author{
Qingguo $\mathrm{Hu}^{\mathrm{a}}$, Zheng Wang ${ }^{\mathrm{b}}$, Yao Zhong ${ }^{\mathrm{c}}$ andJianpeng $\mathrm{Wu}^{\mathrm{d}}$ \\ School of Traffic and Transportaion Engineering,Changsha Universityof Science \& Technology \\ Changsha 410004, China \\ huqg@126.com, 419573597@qq.com,549389589@qq.com,627966872@qq.com
}

Key words: Agent construction system; AHP; Set pair analysis; Dynamic performance Abstract : In this paper, we construct a dynamic model for the evaluation of government investment in the construction of the system. Finally, we get the stable performance evaluation value of the whole construction stage, and verify the feasibility and practicality of the model, so as to provide a reference for the dynamic performance evaluation of the construction project management.

\section{Introduction}

As a new management mode of government investment project, agent construction system has been widely used in our country, it is urgent to establish a set of performance evaluation system which is consistent with the characteristics of the construction project.Scholars Xi Fan ${ }^{[1]}$, Hai-jian Wang $^{[2]}$,Zuo-wei Liu ${ }^{[3]}$ and Jin-Bo Wang ${ }^{[4]}$ and other pay attention to dynamic performance evaluation method research by successively applying contingency theory has made the research on the performance evaluation.Dan-fengXie ${ }^{[5]}$ studied the basic theory of Balanced Scorecard (BSC), and analyzed the shortcomings of the time delay and nonlinear problem of the time delay and nonlinear problem, and proposed a dynamic balanced scorecard (SD-BSC) model with system dynamics (SD).Although domestic and foreign scholars at home and abroad for the construction project performance evaluation method is a lot, but few from the dynamic point of view of the government's investment in the construction of the construction project performance evaluation.Therefore, this article from the government investment in the construction stage of the project implementation stage, through the AHP method and set pair analysis theory, from the time dimension to construct government investment in the construction of the project implementation phase of the dynamic performance evaluation model.

\section{Model construction}

\section{Markov chain state space determination}

In dynamic case, because the Markov chain is the research system state transfer law, it is a method to analyze the future variation law of random events and the possible result. So we analyze the variation rule of the set of element weight and get the comprehensive performance of the object. Consideration set on the similarities and differences of spy change with time and, hypothesis at time $t, N$ characteristics in $S_{t}$ same characters, $P_{t}$ features neither the same nor the opposition, the characteristics of $Q_{t}$ in opposition to each other, and to meet the $S_{t}+P_{t}+Q_{t}=N$. So if will original $N$ characteristics still according to the $\mathrm{S}_{\mathrm{t}}, \mathrm{P}_{\mathrm{t}}, \mathrm{Q}_{\mathrm{t}}$ order rearrange and numbered consecutively and each characteristic in time $t$ after heavy edge numbered corresponding weights $\mathrm{W}_{\mathrm{k}}{ }^{(\mathrm{t})}$, then time $\mathrm{t}$ connection degree: 


$$
\begin{aligned}
& \mu^{(\mathrm{i})}=a^{(i)}+b^{(i)} i+c^{i} j \\
& =\sum_{K=1}^{S_{i}} \omega_{k}^{(t)}+\sum_{K=S_{i}+1}^{S_{i}+p_{i}} \omega_{K}^{(t)} i+\sum_{K=S_{i}+P_{i}+1}^{N} \omega_{K}^{(t)} j
\end{aligned}
$$

among them: $\sum_{K=1}^{S_{i}} \omega_{k}^{(t)}+\sum_{K=S_{i}+1}^{S_{i}+p_{i}} \omega_{K}^{(t)}+\sum_{K=S_{i}+P_{i}+1}^{N} \omega_{K}^{(t)}=1$ 。

If the $\langle\mathrm{A}, \mathrm{B}\rangle$ in $[\mathrm{t}, \mathrm{t}+\mathrm{T}]$ ( $\mathrm{T}$ for the change cycle) the original same anti characteristics have changed, some of the same characteristics remain unchanged, while others are transformed into other with different characteristics. Might as well be in the $\mathrm{t}+\mathrm{T}$ moment, the same characteristics of the original St are still based on the same $S_{t 1}, S_{t 2}$ is neither the same nor the opposition, $S_{t 3}$ became a mutual opposition $\left(\mathrm{S}_{\mathrm{t} 1}+\mathrm{S}_{\mathrm{t} 2}+\mathrm{S}_{\mathrm{t} 3}=\mathrm{S}_{\mathrm{t}}\right)$, the $\mathrm{S}_{\mathrm{t}}$ in $[\mathrm{t}, \mathrm{t}+\mathrm{T}]$ cycle of the transfer vector, and the normalized treatment: $\quad S=\left(M_{11}, M_{12}, M_{13}\right)$

$$
=\left(\sum_{K=1}^{S_{t 1}} \omega_{k}^{(t)}, \sum_{K=S_{t 1}+1}^{S_{t 1}+S_{t 2}} \omega_{k}^{(t)}, \sum_{K=S_{t 1}+S_{t 2}+1}^{S_{t}} \omega_{k}^{(t)},\right) / \alpha^{(t)}
$$

among them:

$$
M_{11}+M_{12}+M_{13}=1 \quad ; \quad \alpha^{(t)}=\sum_{K=1}^{S_{t}} \omega_{K}^{(t)}
$$

Here, assume that $S_{\mathrm{t} 1}, \mathrm{~S}_{\mathrm{t} 2}, \mathrm{~S}_{\mathrm{t} 3}$ in the $\mathrm{S}_{\mathrm{t}}$, the same as the total number of characteristics, differences and the sequence of opposites, because if not, then the total can be re numbered in the above order.

In the same way, the transfer vector of $P_{t}$ is

$$
\begin{aligned}
& P_{t}=\left(M_{21}, M_{22}, M_{23}\right) \\
& =\left(\sum_{K=S_{t}+1}^{S_{t}+P_{t 1}} \omega_{K}^{(t)}, \sum_{K=S_{t}+P_{t 1}+1}^{S_{t}+P_{t 1}+P_{t 2}} \omega_{K=S_{t}+P_{t 1}+P_{t 2}+1}^{(t)}, \sum_{\beta^{(t)}}^{S_{t}+P_{t}} \omega_{T}^{(t)}\right.
\end{aligned}
$$

among them:

$$
\begin{aligned}
& M_{21}+M_{22}+M_{23}=1 ; \quad \beta^{(t)}=\sum_{K=S_{t}+1}^{S_{t}+P_{t}} \omega^{(t)} \\
& P_{t 1}+P_{t 2}+P_{t 3}=P_{t}
\end{aligned}
$$

Qt transfer vector:

$$
Q_{t}=\left(M_{31}, M_{32}, M_{33}\right)
$$

$$
=\left(\sum_{K=S_{t}+P_{t}+1}^{S_{t}+P_{t}+Q_{t 1}} \omega_{K=S_{t}+P_{t}+Q_{t 1}}^{(t)}, \sum_{K=S_{t}+P_{t}+Q_{t 1}+Q_{t 2}+1}^{S_{t}+P_{t}+Q_{t 1}+Q_{t 2}} \omega_{K}^{(t)}, \gamma^{(t)}\right.
$$

among them: $M_{31}+M_{32}+M_{33}=1$

$Q_{t 1}+Q_{t 2}+Q_{t 3}=Q_{t}$

$$
S_{t}+P_{t}+Q_{t}=N \quad ; \quad \gamma^{(t)}=\sum_{K=S_{t}+P_{t}+1}^{N} \omega_{K}^{(t)}
$$


Therefore set pair $\langle\mathrm{A}, \mathrm{B}>$ in $[\mathrm{t}, \mathrm{t}+\mathrm{T}]$ during the same period of the reverse transfer matrix:

$$
M=\left[\begin{array}{lll}
M_{11} & M_{12} & M_{13} \\
M_{21} & M_{22} & M_{23} \\
M_{31} & M_{32} & M_{33}
\end{array}\right]
$$

In the $\mathrm{t}+\mathrm{T}$ time, the set of the contact degree expression is:

$$
\mu^{(t+T)}=a^{(t+T)}+b^{(t+T)} i+c^{(t+T)} j
$$

$=\left(a^{(t)}, b^{(t)}, c^{(t)}\right) \bullet M(1, i, j)$, “•”said matrix multiplication.

Assuming the transfer matrix of each cycle are the same, namely the transfer of the matrix $\mathrm{M}$ is a constant matrix, then $\mathrm{n}$ cycle after $<\mathrm{A}, \mathrm{B}>$ contact degree for:

$$
\begin{aligned}
& \mu^{(t+n T)}=a^{(t+n T)}+b^{(t+n T)} i+c^{(t+n T)} j \\
& =\left(a^{(t)}, b^{(t)}, c^{(t)}\right) M^{n T}(1, i, j)
\end{aligned}
$$

The ergodic properties of Markov chains can be. With the increase of $\mathrm{M}^{\mathrm{nT}}$, the $\mathrm{n}$ will be stable.Therefore, the contact degree of the $t$ moment after multiple cycles of the transfer.. By the following equations can be obtained stable connection degree: $\left\{\begin{array}{c}(a, b, c)(I-M)=0 \\ a+b+c=1\end{array}\right.$ among them, $a, b, c>0, I$ is Unit matrix.

\section{Case application}

\section{Determine the weights of the Markov chain of the time step.}

In this paper, according to the field survey of the project, the data related to the project performance indicators were collected, and the weight of the two indicators was determined by AHP method. Through the expert scoring method, the index can be divided into gradeI $\sim$ III. Which I represents a good performance management requirements; II represents a good, said and performance management requirements vary; III, the general, does not meet the requirements of project performance management. And determine the level of the evaluation of the material matrix, the level of the two indicators in each evaluation cycle of evaluation, the results are shown in Table 1. 
Table 1 On the two levels of the dynamic performance of the management of the construction phase of the construction project

\begin{tabular}{|c|c|c|c|c|c|c|}
\hline First level indicator & Two level indicator & Weight & $\begin{array}{l}\text { One } \\
\text { quarter }\end{array}$ & $\begin{array}{l}\text { Two } \\
\text { quarter }\end{array}$ & $\begin{array}{l}\text { Three } \\
\text { quarter }\end{array}$ & $\begin{array}{l}\text { Four } \\
\text { quarter }\end{array}$ \\
\hline \multirow[b]{2}{*}{ Quality assurance A1 } & Rework loss rate A11 & 0.128 & I & I & III & I \\
\hline & $\begin{array}{l}\text { Excellent and good rate of } \\
\text { branch sub item A12 }\end{array}$ & 0.016 & III & II & I & II \\
\hline \multirow{2}{*}{$\begin{array}{l}\text { Contract } \\
\text { management A2 }\end{array}$} & Contract implementation A21 & 0.048 & II & III & III & II \\
\hline & $\begin{array}{l}\text { Contract modification and claim } \\
\text { handling A22 }\end{array}$ & 0.052 & I & I & II & I \\
\hline \multirow{2}{*}{$\begin{array}{l}\text { Fund management } \\
\text { A3 }\end{array}$} & $\begin{array}{l}\text { Project investment target } \\
\text { completion rate } \mathrm{A} 31\end{array}$ & 0.150 & III & III & I & III \\
\hline & $\begin{array}{l}\text { Cost deviation A32 } \\
\text { Fund in place rate } \mathrm{A} 33\end{array}$ & 0.145 & I & I & III & II \\
\hline $\begin{array}{l}\text { Schedule } \\
\text { management A4 }\end{array}$ & Progress deviation A41 & 0.052 & II & $\begin{array}{l}\text { II } \\
\text { II }\end{array}$ & III & II \\
\hline \multirow{2}{*}{$\begin{array}{l}\text { Safety civilization } \\
\text { construction } \\
\text { management A5 }\end{array}$} & $\begin{array}{l}\text { Implementation of safety } \\
\text { production management A51 }\end{array}$ & 0.114 & I & II & I & III \\
\hline & $\begin{array}{l}\text { Environmental protection, } \\
\text { civilized construction test } \\
\text { market A52 }\end{array}$ & 0.064 & III & I & II & II \\
\hline \multirow{2}{*}{$\begin{array}{l}\text { Comprehensive } \\
\text { management A6 }\end{array}$} & $\begin{array}{l}\text { Information document } \\
\text { management A61 }\end{array}$ & 0.050 & I & II & III & III \\
\hline & $\begin{array}{l}\text { Project coordination } \\
\text { performance A62 }\end{array}$ & 0.064 & I & III & II & I \\
\hline $\begin{array}{l}\text { Project management } \\
\text { satisfaction A7 }\end{array}$ & Using unit satisfaction A71 & 0.039 & II & I & I & I \\
\hline
\end{tabular}

\section{Dynamic evaluation of management performance of agent construction project}

In this paper, we use the quarterly data of Table 1 to analyze the performance of the project construction management, from table 2 data, we can calculate the degree of connection between the $1 \sim 4$ quarters of the project construction phase and the same as the different anti transfer matrix:

$$
\begin{aligned}
M_{1-2} & =\left[\begin{array}{lll}
0.537 & 0.357 & 0.106 \\
0.291 & 0.473 & 0.236 \\
0.070 & 0.652 & 0.278
\end{array}\right] M_{2-3}=\left[\begin{array}{lll}
0.091 & 0.271 & 0.638 \\
0.168 & 0.419 & 0.413 \\
0.183 & 0.244 & 0.573
\end{array}\right] \\
M_{3-4} & =\left[\begin{array}{lll}
0.122 & 0.470 & 0.408 \\
0.276 & 0.500 & 0.224 \\
0.111 & 0.604 & 0.285
\end{array}\right] \\
\mu_{1} & =0.605+0.165 i+0.23 j \mu_{2}=0.428+0.31 i+0.262 j \\
\mu_{3} & =0.319+0.232 i+0.449 j \mu_{4}=0.283+0351 i+0.366 j
\end{aligned}
$$

\section{The results of the evaluation are obtained}

In accordance with the proportion of total investment in the total investment in the construction phase of the total investment, the weight of the transfer matrix, which is divided into $\mathrm{W}=(0.30,0.36$, 0.34 ), the construction phase of the $1 \sim 4$ quarter weighted evaluation of the transfer matrix is:

$$
M=\left[\begin{array}{lll}
0.235 & 0.343 & 0.400 \\
0.242 & 0.463 & 0.296 \\
0.125 & 0.489 & 0.387
\end{array}\right]
$$


Then the $i=a^{(t)} /\left(a^{(t)}+c^{(t)}\right)$ and $\mathrm{j}=-1$ are calculated by using the similarity degree of similarity, and the relationship of the performance of each quarter is obtained: $\mathrm{U}_{1}=0.495, \mathrm{U}_{2}=0.358, \mathrm{U}_{3}=-0.034, \mathrm{U}_{4}=0.070$. From the table 2, the performance of the project construction phase of the quarter is very unstable. 1 quarter is excellent, the 2 quarter is good, the 3 quarter is the general, and the 4 quarter is poor, the entire project construction stage management performance is declining trend. If the transfer matrix $M$ remains constant, then the performance of the project construction stage is obtained by the following equation:

$$
\left\{(a, b, c)\left[\begin{array}{ccc}
0.765 & -0.343 & -0.400 \\
-0.242 & 0.537 & -0.296 \\
-0.125 & -0.489 & 0.613
\end{array}\right]=0\right.
$$

Solution equation set: $a=0.200, \mathrm{~b}=0.448, \mathrm{c}=0.352$, the stability of the contact degree is $\mathrm{U}=0.2+0.448 \mathrm{i}+0.352 \mathrm{j}$, according to the similarity degree of $\mathrm{i}=0.362, \mathrm{j}=-1, \mathrm{U}=0.01$. From table 2 it can be seen that the construction stage of the construction system project management and stability performance is generally determined.

Table 2 management performance evaluation grade of construction stage of construction project

\begin{tabular}{c|c|c|c|c}
\hline Grade & Excellent & Good & Generally & Poor \\
\hline $\begin{array}{c}\text { Evaluation } \\
\text { value }\end{array}$ & $1-0.4$ & $0.4-0.3$ & $0.3-0$ & $<0$ \\
\hline
\end{tabular}

\section{Conclusion}

This article from the construction phase of the construction phase of the dimension, the construction phase of the construction phase is divided into four quarters of the evaluation cycle. The dynamic performance evaluation index was evaluated by using the model of material element analysis. Then, the dynamic performance evaluation of each evaluation cycle is carried out by constructing a set of Markov chain. Finally, the stable performance evaluation value of the whole construction stage is obtained, and the following conclusions are obtained:(1) Using matter element analysis method, the complex correlation between the index and the correlation degree of each index and grade was solved. In each cycle of the evaluation process, can be timely feedback of the indicators, the follow-up work can continue to improve.(2) On the basis of the traditional set pair analysis, the paper introduces the element weight, constructs a set of Markov chain based on the analysis of dynamic change equation, describes the same anti transfer law, can well predict the development trend of the performance, the whole stage of the performance evaluation is more accurate, scientific and public.

\section{Acknowledgement}

This work was financially supported by the Hunan Provincial Department of Education Science Research Key Project (14A007).

\section{References}

[1] Xi Pan. Research on the dynamic performance evaluation of the construction projects of the housing construction project based on the agent construction model[D]. Chong Qi: Chongqing 
jiaotong University, 2014

[2] Jianhai Wang. Research on the performance evaluation of construction system of engineering projects [D].Qing dao: China University of Petroleum, 2010

[3] Zuowei Liu. The research on the performance evaluation of government investment in construction projects in China [D]. Qinhuangdao: Yanshan University, 2012

[4] Jinbo Wang. Research on the dynamic management of the whole life cycle of engineering projects based on PDPC method [D]. Hangzhou: Zhejiang University, 2013

[5] Danfeng Xie, Yanhai Gong, Shurong Guo. Performance evaluation of integrated management of engineering projects based on dynamic model [J]. Scientific and technological progress and Countermeasures, 2013,30 (13): 63-67. 